\title{
Developing Saudi EFL Students' Reading Skills Through Schema-Based Techniques
}

\author{
Faisal Mutair Rhail Alshammari \\ Department of English, Ministry of Education, Hail, Saudi Arabia
}

Email address:

fmfm_9000@hotmail.com

\section{To cite this article:}

Faisal Mutair Rhail Alshammari. Developing Saudi EFL Students' Reading Skills Through Schema-Based Techniques. International Journal of Applied Linguistics and Translation. Vol. 3, No. 2, 2017, pp. 16-23. doi: 10.11648/j.ijalt.20170302.11

Received: March 1, 2017; Accepted: March 1, 2017; Published: May 6, 2017

\begin{abstract}
Reading is one of the main four language skills. As a receptive skill, it enables learners to receive a significant comprehensible input which can be used later on in speaking or in writing. Research indicates that reading comprehension is a highly complex, interactive, constructive process in which students actively reconstruct the original intentions of the writer (s) by drawing on what they already know to make use of the new knowledge. The researcher examined the impact of schemabased techniques on developing Saudi first-year secondary school students' reading comprehension skills. Thirty five students representing the experimental group students were taught through the schema-based techniques, while a class of thirty eight students receiving regular instruction represented the control group. A pre-post reading comprehension test was given to the two groups before and after the treatment. Results provided support for the four hypotheses of the study. The experimental group out-performed the control group on the post-test in overall reading comprehension as well as in each reading comprehension skill. Furthermore, the experimental group students achieved tangible progress in their reading comprehension after being taught through schema-based techniques. Hence, these positive findings of the study proved the effectiveness of schema-based techniques in developing first-year secondary school students' overall reading comprehension and each reading comprehension skill as well.
\end{abstract}

Keywords: Schema Theory, EFL Students, Reading and Comprehension Skills

\section{Introduction}

Among the main four language skills, reading is of vital importance. It is a receptive skill that enables learners to receive a significant comprehensible input. Such an input can be used later on in writing and speaking. Li and Zang (2016) state that reading is a fundamental means of enhancing students' learning the language. Research on reading comprehension indicates that readers rely on their prior knowledge and world experience when trying to comprehend a text. It is this organized knowledge that is referred to as schema (plural schemata). According to Maria (1990), the learner's existing schemata, which are integrated structures of knowledge about a given topic, play a critical role in new learning. Schemata include underlying objects, situations, events, actions, and sequences of actions for use in interpreting new experiences.

Schema theory is an important concept directly related to interactive views of the reading comprehension process that has had a major impact on both reading research and instruction. A powerful feature of schema theory is that it helps to better understand how new learning is integrated with the knowledge an individual already possesses. Research on schema theory and reading comprehension indicates that the task of teaching reading becomes helping students build the appropriate background knowledge they need, and teaching them that reading is an interactive process of activating prior knowledge with textual input in order to build new knowledge. Schemata provide the mental scaffolding that readers use to make sense of incoming information and trigger the cues used in the systematic searching of memory when the information must be recalled. They guide the reader in distinguishing the important from the trivial, and in selecting the degree of attention to give to different parts of a text (Kitao, 1987). In second/foreign language reading classes, this implies that criteria for selecting instructional materials should include the familiarity of the background, especially at lower language 
proficiency levels. Reading activities should be specifically designed to activate a schema that will be helpful to the reader. Simultaneously, students should be provided with enough background information before they start reading to orient them to the text and to help them activate whatever relevant previous knowledge they may already have.

Zhao and Zhu (2012) state that schema theory is effectively in developing students' reading skills and improving their reading abilities. Similarly, schema-based techniques have proved very effective in developing learners' reading skills as many studies have shown (Bottomley and Osborn, 1993; Ciardiello, 1998; Lysynchuk, 1989; Odafe, 1998; Palincsar, 1987). If students lack sufficient schemata, they can be helped to build new schemata by asking questions that will make the transition from their current knowledge to new knowledge. The purpose of such a process is to help student acquire a reading schema that emphasizes the reader's purposes and the dynamic interaction between reader and the printed page. Basic to this process is also the point that meaning does not lie "in text" and that what students already know will affect what they can come to know. The current study employs schema-based techniques to develop Saudi EFL students' reading skills.

\subsection{Problem \& Questions of the Study}

Based on the researcher's experience as EFL instructorat secondary schools in Saudi Arabia, some observations were made. First, reading comprehension is not given adequate consideration in Saudi secondary schools. Most teachers ask their students to pay attention to grammar rules and identifying and learning individual words in isolation. Second, students are encouraged to produce words and sentences directly stated in passages when answering comprehension questions in their textbooks. Third, most teachers restrict their role to explaining difficult words and grammatical points and translating the whole text into Arabic. It can be concluded that these procedures are not enough or appropriate to develop students' reading skills.

The study problem can be identified in first-year secondary students' poor mastery of reading skills. Therefore, the current study attempted to develop reading comprehension skills for first-year secondary students through the use of schema-based techniques. In other words, the study provided answers to the following questions:

- How far are schema-based techniques effective in developing the students' reading comprehension?

- How far are schema-based techniques effective in developing each of the following reading skills (identifying the main idea, identifying specific stated information or details, identifying cause and effect relationship, guessing the meaning of unknown words or phrases, making inferences, making comparisons, distinguishing between facts and opinions, and drawing conclusions)?

\subsection{Hypotheses of the Study}

It was hypothesized that:

- There are statistically significant differences between the mean scores of the experimental group students who are instructed through to use schema-based techniques and the control group who receive regular instruction in favor of the experimental group on the overall reading post-test.

- There are statistically significant differences between the mean scores of the experimental group students and the control group students in favor of the experimental group students in each reading skill on the reading posttest.

- There are statistically significant differences between the mean scores of the experimental group students on the overall reading pre-test and post-test in favor of the post-test.

- There are statistically significant differences between the mean scores of the experimental group students on the pre-test and the post-test in favor of the post-test in each reading skill.

\section{Literature Review}

Schema theory originated with the studies of cognition by the cognitive psychologist Bartlett (1932). According to this theory, all prior knowledge is packaged into units (or schemata). Each schema (or unit) is an abstract structure of knowledge and embedded in each schema is, in addition to the knowledge itself, information about how this prior knowledge can be used to facilitate the interpretation of new written or oral knowledge (Anderson \& Lynch, 1988; Landry, 2002; Rumelhart, 1980).

Schemata are higher-level abstract complex knowledge structures (Wilson and Anderson, 1986) that function as "ideational scaffolding" (McNeil, 1987). A schema is structured as it indicates relationships among constituent concepts; it is abstract as a single schema can cover a number of texts that differ in particulars. Hence, schemata are the learners' concepts, beliefs, expectations and processes based on their past experiences that can be used in making sense of texts and new knowledge (McNeil, 1987). In other words, schemata are prototypical or generic characterizations of objects, events and situations (Armbruster, 1986). They are mental structures, consisting of relevant individual knowledge, memory, and experience, which allow individuals to incorporate what they learn into what they know.

Moffitt (1989, pp. 16-17) views schemata as "organized, structured, clustered and abstract bodies of information that are generally conceptualized as networks of information in which the relationships among facts and actions are specified." In other words, schemata are the underlying connections that allow new experiences and information to be aligned with previous knowledge (McCarthy, 1991). Thus, a schema is a cognitive structure (mental map/ file) 
composed of learners' integrated prior experiences and knowledge (Harris and Hodges, 1995). On his part, Oller (1995, p. 276) defines a schema as "the kind of organization that enables its user to handle certain kinds of tasks more efficiently than would otherwise be possible".

Thus, schema theory is a theory of memory and language processing based on the notion that past experiences and background knowledge lead to the creation of mental frameworks that help learners make sense of new experiences (Nunan, 1999). It suggests that comprehension is an interactive process involving learners' background knowledge of any kind - including knowledge of the content of the text, the context, the culture and/or the conventions of the spoken or written language. Thus, comprehension takes place when "the first part of a text activates a schema ... which is either confirmed or disconfirmed by what follows"(Wallace, 1992, p. 33). Furthermore, according to this theory, learners can hardly comprehend texts or utterances for which they do not have some kind of existing prior knowledge structure or schema (Scarcella and Oxford, 1992).

In relation to reading comprehension, schema theory provides the following important functions to language learners (Clark, 1990; D' Andrade, 1995; McNeil, 1987; Wilson and Anderson; 1986). First, schemata can help learners to judge the importance and familiarity level of the information included in the spoken or written texts, thus directing them to pay more attention to what is more important or less familiar. Second, schemata can help learners make successful inferences that go beyond the literally stated information within a given text, thus ensuring successful interpretation of its explicit and, more importantly implicit information. Third, schemata can help learners compose summaries of given oral or written discourses focusing on the main idea (s) expressed in those discourses and disregarding less important details by providing them with criteria to judge the relative importance of different information within a given discourse. Fourth, schemata can facilitate learners' recall of new information as they facilitate interpretation of given texts in the first place and when these schemata are activated, they help learners recall what they heard or read by creating more memory cues. Fifth, when activated, schemata facilitate learners' orderly search for relevant information in a way that permits inferential reconstruction of missing information within a given text. Sixth, schemata are the slots for assimilating additional information. They fill gaps in the new knowledge, supply conventional details and change some ideas- using a schema for dessert, it is easy to augment the familiar ice cream and cake with the new instance flan.

According to Scarcella and Oxford (1992, p. 96) a synthesis of research work on reading comprehension and schema theory reveals that: (1) lack of schemata or the failure to activate an appropriate schema can significantly impair comprehension; (2) appropriate content/ rhetorical schema can increase comprehension; (3) background knowledge can be just as important as language ability in terms of comprehension; and (4) comprehension is facilitated by explicitly inducing schemata through pre- reading activities.

\subsection{Schema-Based Techniques and Developing Learners' Reading Comprehension}

Several schema-based techniques have proved effective in developing language learners' reading skills. Among these effective techniques are KWL and DRTA. These techniques are not fixed and isolated techniques but flexible and interchangeable. It is up to the teacher to decide when to use either technique or a combination. They are context independent and can be adapted to any classroom learning situation.

\subsubsection{Directed Reading-Thinking Activity (DRTA)}

Stauffer (1975) advocated teaching students to raise questions in order that they may become reading-thinking scholars. DRTA is one of the first techniques that has attempted to teach children how to understand what they are reading by encouraging them in the active processing of text. A teacher's plan of action in the DRTA is: (1) to activate students' thoughts before reading by asking such questions as, "What do you think?" (2) to agitate reflective thought by asking, "Why do think so?" and (3) to require evidence in support of the conclusion in the form of references to the text and peer judgments regarding the force of the arguments (Maria, 1990).

\subsection{2. $K W L$}

KWL (What I know, What I Want to Know, What I Learned), developed by Ogle (1986), is an educational technique used for building upon students' prior knowledge so that they could successfully begin generating questions. Since its earliest formal recognition, KWL has helped learners develop appropriate questions for research and for organizing what they know. In recent years, KWL has been revised to address emerging educational needs. For example, in KWLQ (Schmidt, 1999) learners develop further questions for study.

\subsection{3. $K W L Q$}

After consultation, discussion, and reflection with workshop leaders, teachers began using a modified version of Ogle's (1986) KWL for reading comprehension. They added a Q, and the resulting KWLQ (Schmidt, 1999) became a useful technique to help children frame questions in a consistent format throughout inquiry units of study. For K, what I Know, students recorded prior knowledge of a topic. For W, what I Want to learn, they generated questions about the topic. Next, the students read, talked to people, visited places, viewed videos, and explored the internet to find answers to their questions. For L, what I Learned, the students recorded and explained aloud the information discovered. Finally, Q encouraged more questions, so that students would see that learning is a continuous quest; excellent research should lead to more questions for further study. KWLQ served as a means for creating a questioning atmosphere for systematic recording and reporting. Students 
constructed meaning as they searched for the answers to their own as well as their classmates' questions.

\subsection{Related Studies}

A lot of research has been conducted on the role of schema-based techniques in developing learners' reading comprehension. For example, Johnstone (1989) compared the evaluations of junior and senior pre-service teachers, supervising teachers, and reading specialists who observed a students' performance using the DRTA. Four groups participated in the. Group one had 12 elementary education juniors who had just completed a methods course in reading. Group two had 18 elementary education seniors who completed the student teaching semester. Group three had 13 supervising teachers, and group four had 28 reading specialists. The instrument used to evaluate student performance consisted of nine categories-three of which related to teaching in general and six of which directly pertained to the DRTA. Results indicated that pre-service teachers' ratings of student performance using the DRTA compared favorably with those of their supervising teachers. There was agreement in the ratings of the juniors and seniors with the supervising teachers in each of the six competencies that are directly related to the DRTA.

Spires (1990) explored the effects of a prior knowledge activation strategy on students' ability to successfully engage in the ongoing comprehension of extended text. Data were obtained from 79 ninth graders enrolled in a social studies class. Equal numbers of high and low readers were assigned to each of three treatment groups: prior knowledge activation (PKA) group; main idea (MI) group; and control group. All subjects participated in eight 45-minute instructional sessions followed by four 45-minute testing sessions (three immediate testing sessions and one delayed testing session 4 weeks later). Naturalistic reading passages were selected from the social studies textbook that the students were using, and instructors were mixed across treatments to control for an instructor effect. Results revealed that explicit instruction in how to spontaneously activate prior knowledge during reading had a positive effect on students' ability to answer application level questions. Results also revealed that the PKA strategy did not have a significant effect on literal comprehension, and that the MI group performed better on the literal measure, since the treatment focused on encouraging students to target main ideas and supporting details rather than to elaborate from the text.

Zhao and Zhu (2012) did a study to explore the role of the schema theory in developing EFL Chinese students' reading skills. The treatment was on schema activation and construction in a college EFL reading class. The researcher employed schema theory throughout the whole reading process through several schema-based activities before, during and after reading comprehension lessons. Results indicated that the application of schema theory activities was significantly valuable in cultivating the students' reading interest, raising their rate of reading speed, and developing their reading skills.
From the previous survey of theoretical background, the researcher concludes that schema theory suggests that reading comprehension is an interactive relationship or process involving the reader's background knowledge and the text; it involves actively constructing meaning among the parts of the text and personal experience. In this process, schema-based techniques such as KWL and DRTA place the responsibility for learning on the students and motivate them to engage in a continuous learning process. Teachers can maximize the benefits of students' learning by using pictures, titles, and so on, to activate students' appropriate schemata and to help them get engaged in the learning process.

\section{Methodology}

\subsection{Design of the Study}

The quasi-experimental design called the non-equivalent group design was employed. Two intact classes were randomly selected; one class (35 students) taught through the schema-based techniques for teaching reading represented the experimental group and another class (38 students) receiving regular instruction represented the control group. A pre-post reading comprehension test was given to the two groups before and after the treatment.

\subsection{Participants}

Participants in this study were first-year students from Prince Sultan Secondary School in Riyadh, Saudi Arabia. The students in the experimental group (35 students) were the students taught by the researcher. On the other hand, the students in the control group (38 students) received regular instruction by their classroom instructor.

\subsection{Procedure}

The researcher taught the experimental group students through schema-based techniques for developing their reading comprehension skills. These techniques prompted students to ask their own questions (based on their prior knowledge) in order to reach answers that they wanted to know.

\subsection{Schema-Based Techniques Used with the Experimental Group Students}

The techniques used in implementing schema theory in the classroom were not fixed and isolated techniques but flexible and interchangeable. So, the researcher used either technique or a combination even within the same lesson.

\subsubsection{DRTA}

In this technique, the researcher began by asking students to predict the text and set a purpose for reading. Then, the students read a section of a story or content area material. The researcher asked them to stop at a point where he felt they should have enough information to make an accurate prediction about the next section. The researcher asked four kinds of questions basic to the DRTA technique: (1- What do 
you think a story with a title like this might be about?, 2What do you think now?, 3- What in the story makes you think that? and 4- What do you think will happen next?)

\subsection{2. $K W L Q$}

In order to help the students relate to prior knowledge, the researcher used KWLQ. For K, what I Know, the students recorded prior knowledge of a topic. For W, what I Want to learn, they generated questions about the topic. Next, the students read, talked to each other and conversed with the researcher. For L, what I Learned, the students recorded and explained aloud the information discovered. Finally, Q encouraged more questions, so that the students would see that learning is a continuous quest. Thus, this technique encouraged more questions for further study.

\subsection{Instrument of the Study}

The researcher used a pre-post reading test to measure the students' reading comprehension skills.

\subsection{Purpose of the Test}

After determining the appropriate reading skills for first-year secondary school students, the reading comprehension test was used as a pre-posttest. It was used as a pre-test to make sure that the students of both groups were at the same reading level before starting the experiment; and hence the progress achieved by the experimental group would be attributed to the teaching they received using schema-based techniques. As a post-test, it was used to investigate the effectiveness of students' schema-based techniques in developing the experimental group students' reading comprehension skills.

\subsection{Validity Test}

To measure the test content validity, the first version of the test was given to 6 TEFL professors, assistant professors and college staff to evaluate each question in terms of content and level of comprehension measured. Moreover, they were asked to evaluate the test as a whole in terms of: correctness, number of questions, and difficulty of the reading texts. The test proved to be mostly a valid one as the jury approved most of the questions and suggested the following: (1- Modifying some of the questions in terms of words selected to be easier for the students to understand, 2- Modifying some distracters of M. C. Q to be more attractive for the students, 3- Modifying or omitting some questions, because they asked for the same pieces of information so that they would not be any repetition in questions, and 4Distributing the number of questions to cover the eight reading comprehension skills in a balanced way).

\subsection{Reliability Test}

In order to establish the reliability of the test, it was administered to a randomly chosen group of 32 students in first-year secondary school students at Prince Sultan Secondary School in Riyadh. These students were neither included in the experimental group nor in the control group. Then, the test was administered one more time after two weeks to the same 32 students. The correlation between the two administrations was 0.87 which is high.

\section{Results and Discussion}

The results are presented in relation to developing Saudi EFL students' reading skills through schema-based techniques. First of all, a comparison between the experimental and control groups on the pre-test was conducted using t-tests for independent samples to examine if there were any statistically significant differences between the two groups before the treatment. The following table shows that there was no statistically significant difference between the experimental and control groups on the pre-test in overall reading comprehension.

Table 1. T-test results of the pre- test comparing the control and the experimental groups in overall reading comprehension.

\begin{tabular}{lllllll}
\hline Group & N & M & S. D. & D. F. & t value & $\begin{array}{l}\text { Significance } \\
\text { level }\end{array}$ \\
\hline Control & 38 & 16.18 & 4.04 & 71 & 0.11 & $\begin{array}{l}\text { Not significant } \\
\text { at } 0.05 \text { level }\end{array}$ \\
Experimental & 35 & 16.08 & 4.22 & & & \\
\hline
\end{tabular}

As shown in table 1 and through comparing the estimated t- value $(0.11)$ for the two groups on the pre- test to the statistical t-value (1.99) at 0.05 level, it was found that the estimated t- value was not statistically significant.

In the same way, independent samples t-tests for the differences between the experimental and control groups on the pre- test were conducted with respect to each reading comprehension skill. This was done to make sure that there were no statistically significant differences between the two groups on the pre- test in reading each comprehension skill as shown in table 2 .

Table 2. T-test results of the pre-test comparing the control and the experimental groups in each reading comprehension skill.

\begin{tabular}{|c|c|c|c|c|c|c|c|}
\hline \multirow[t]{2}{*}{ Reading Comprehension Skill } & \multicolumn{2}{|c|}{$\begin{array}{l}\text { Experimental } \\
\text { Group Pre- test }\end{array}$} & \multicolumn{2}{|c|}{$\begin{array}{l}\text { Control Group } \\
\text { Pre- test }\end{array}$} & \multirow[t]{2}{*}{ DF } & \multirow[t]{2}{*}{ T value } & \multirow[t]{2}{*}{ Significance Level } \\
\hline & M & S. D & M & S. D & & & \\
\hline 1. Identifying the main idea & 2.00 & 0.69 & 1.93 & 0.58 & 71 & 0.11 & Not Significant at 0.05 Level \\
\hline 2. Identifying specific stated information or details & 2.24 & 1.10 & 2.35 & 1.03 & 71 & -0.10 & Not Significant at 0.05 Level \\
\hline 3. Identifying cause and effect relationship & 1.87 & 0.91 & 2.32 & 1.23 & 71 & -0.41 & Not Significant at 0.05 Level \\
\hline 4. Guessing the meaning of unknown words or phrases & 1.71 & 0.86 & 1.45 & 0.92 & 71 & 0.32 & Not Significant at 0.05 Level \\
\hline 5. Making inferences & 1.68 & 1.12 & 1.79 & 0.84 & 71 & -0.11 & Not Significant at 0.05 Level \\
\hline 6. Making comparisons & 2.68 & 1.83 & 2.21 & 1.96 & 71 & 0.24 & Not Significant at 0.05 Level \\
\hline 7. Distinguishing between facts and opinions & 1.97 & 0.79 & 1.68 & 0.53 & 71 & 0.43 & Not Significant at 0.05 Level \\
\hline 8. Drawing conclusions & 1.39 & 1.00 & 1.55 & 0.76 & 71 & -0.18 & Not Significant at 0.05 Level \\
\hline
\end{tabular}


Table 2 shows that there were no statistically significant differences between the mean scores of the experimental and control groups on the pre- test in each reading comprehension skill. This means that the two groups were approximately at the same level of reading comprehension at the beginning of the experiment. It can be also noticed from the previous table that the mean scores of both groups are low.

\subsection{Results Related to the Study Hypotheses Are as Follows}

Before presenting the study results related to each hypothesis, it is important to refer to the previously mentioned fact that there are two sets of hypotheses. The first set includes those hypotheses concerned with the comparison between the control and experimental groups on the post-test. As for the second set, it includes those hypotheses focusing on the pre-post reading comprehension of the experimental group with respect to each variable.

\subsubsection{Hypotheses Concerned with the Comparison Between the Experimental and Control Groups on the Post-Test \\ a. Hypothesis One}

There is a statistically significant difference between the mean scores of the experimental group students exposed to schema-based techniques and the control group students receiving regular instruction on the post-test in overall reading comprehension in favor of the experimental group students.

In order to verify the validity of this hypothesis, a t-test for independent samples was used to compare the mean scores of the two groups on the post-test. The results of the t-test proved to be statistically consistent with the hypothesis as shown in table 3 .

Table 3. T-test results of the post-test comparing the experimental and control groups in overall reading comprehension.

\begin{tabular}{lllllll}
\hline Group & N & M & S. D. & D. F. & t value & $\begin{array}{l}\text { Significance } \\
\text { Level }\end{array}$ \\
\hline Control & 38 & 20.29 & 2.97 & 71 & 14.83 & $\begin{array}{l}\text { Significant at } \\
\text { Experimental }\end{array}$ \\
35 & 28.03 & 1.24 & 71 Level \\
\hline
\end{tabular}

The previous table shows that the estimated $t$ value (14.83) was statistically significant at 0.01 level. Thus, it can be safely said that there was a statistically significant difference between the experimental and control groups on the post-test in overall reading comprehension in favor of the experimental group. So, the first hypothesis was confirmed.

\section{b. Hypothesis Two}

There are statistically significant differences between the mean scores of the experimental group students and the control group students on the post-test in each reading comprehension skill in favor of the experimental group students.

T-tests for independent samples were conducted in order to compare the post-test mean scores of the experimental and control groups in each reading comprehension skill. The results of the t-tests proved to be statistically consistent with the above stated hypothesis. Therefore, the second hypothesis was accepted. Table 4 shows this statistical significance for each reading comprehension skill.

Table 4. T-test results of the post-test comparing the experimental and the control groups in each reading comprehension skill.

\begin{tabular}{|c|c|c|c|c|c|c|c|}
\hline \multirow{2}{*}{ Reading Comprehension Skill } & \multicolumn{2}{|c|}{$\begin{array}{l}\text { Experimental } \\
\text { Group Post-test }\end{array}$} & \multicolumn{2}{|c|}{$\begin{array}{l}\text { Control Group } \\
\text { Post-test }\end{array}$} & \multirow{2}{*}{ D. F. } & \multirow{2}{*}{ T value } & \multirow{2}{*}{ Significance Level } \\
\hline & $\mathbf{M}$ & S. D. & $\mathbf{M}$ & S. D. & & & \\
\hline Identifying specific stated information or details & 3.92 & 0.27 & 2.79 & 0.04 & 71 & 9.24 & Significant at 0.01 Level \\
\hline Identifying cause and effect relationship & 3.97 & 0.16 & 3.47 & 0.83 & 71 & 3.65 & Significant at 0.01 Level \\
\hline Making inferences & 3.76 & 0.54 & 2.03 & 0.85 & 71 & 10.59 & Significant at 0.01 Level \\
\hline Making comparisons & 5.63 & 0.49 & 3.66 & 1.65 & 71 & 7.08 & Significant at 0.01 Level \\
\hline Distinguishing between facts and opinions & 3.00 & 0.00 & 2.53 & 0.56 & 71 & 5.24 & Significant at 0.01 Level \\
\hline Drawing conclusions & 2.84 & 0.44 & 1.84 & 0.82 & 71 & 6.62 & Significant at 0.01 Level \\
\hline
\end{tabular}

Table 4 shows that the estimated $\mathrm{t}$ values statistically significant at 0.01 level on the reading post-test in each reading skill in favor of the experimental group students.

\subsubsection{Hypotheses Focusing on the Comparison Between the Pre-Post Reading Comprehension Performance of the Experimental Group}

a. Hypothesis Three

There is a statistically significant difference between the mean scores of the experimental group students on the pretest and the post-test in overall reading comprehension in favor of the post-test scores.

To determine the relative extent of change fostered by the implementation of schema-based techniques from the pretest to the post-test for the experimental group, a paired samples t-test was used. This t-test aimed at comparing the mean scores of the experimental group on the pre- test and the post-test in overall reading comprehension. See table 5 . 
Table 5. T-test results comparing the pre-test vs. post-test means for the experimental group in overall reading comprehension

\begin{tabular}{|c|c|c|c|c|c|c|c|}
\hline Test & $\mathbf{N}$ & M & S. D. & D. F. & T value & Significance Level & Effect Size \\
\hline $\begin{array}{l}\text { Pre- test } \\
\text { Post-test }\end{array}$ & 35 & $\begin{array}{l}16.08 \\
28.03\end{array}$ & $\begin{array}{l}4.22 \\
1.24\end{array}$ & 34 & -21.80 & Significant at 0.01 Level & $\begin{array}{l}-5.07 \\
\text { Large }\end{array}$ \\
\hline
\end{tabular}

Table 5 indicates that there was a statistically significant difference at 0.01 level in overall reading comprehension between the mean scores of the experimental group on the pre-test and the post-test in favor of the post-test since the estimated t- value was $(-21.80)$. Thus, it can be safely said that the t-test results proved to be statistically consistent with the hypothesis. Therefore, the third hypothesis was confirmed.

\section{b. Hypothesis Four}

There are statistically significant differences between the mean scores of the experimental group students on the pre- test and the post-test in favor of the post-test in each reading skill.

In order to verify the validity of this hypothesis, paired samples t-tests were used. The t-test results (in table 6) proved that there were statistically significant differences at 0.01 level between the mean scores of the experimental group on the pre-test and the post-test in each reading comprehension skill. In other words, the results of the t-tests proved to be statistically consistent with the above stated hypothesis. Therefore, the fourth hypothesis was accepted.

Table 6. T-test results comparing the pre-test vs. post-test means for the experimental group in each reading comprehension skill.

\begin{tabular}{|c|c|c|c|c|c|c|c|}
\hline \multirow[t]{2}{*}{ Reading Comprehension Skill } & \multicolumn{2}{|c|}{$\begin{array}{l}\text { Experimental } \\
\text { Group Pre- test }\end{array}$} & \multicolumn{2}{|c|}{$\begin{array}{l}\text { Experimental } \\
\text { Group Post-test }\end{array}$} & \multirow[t]{2}{*}{ D. F. } & \multirow[t]{2}{*}{ T value } & \multirow[t]{2}{*}{ Significance Level } \\
\hline & M & S. D. & $\mathbf{M}$ & S. D. & & & \\
\hline Identifying the main idea & 2.00 & 0.69 & 2.89 & 0.31 & 34 & -3.58 & Significant at 0.01 Level \\
\hline Identifying specific stated information or details & 2.24 & 1.10 & 3.92 & 0.27 & 34 & -9.72 & Significant at 0.01 Level \\
\hline Identifying cause and effect relationship & 1.87 & 0.91 & 3.97 & 0.16 & 34 & -14.05 & Significant at 0.01 Level \\
\hline Guessing the meaning of unknown words or phrases & 1.71 & 0.86 & 3.00 & 0.00 & 34 & -9.05 & Significant at 0.01 Level \\
\hline Making inferences & 1.68 & 1.12 & 3.76 & 0.54 & 34 & -13.22 & Significant at 0.01 Level \\
\hline Distinguishing between facts and opinions & 1.97 & 0.79 & 3.00 & 0.00 & 34 & -8.03 & Significant at 0.01 Level \\
\hline Drawing conclusions & 1.39 & 1.00 & 2.84 & 0.44 & 34 & -9.39 & Significant at 0.01 Level \\
\hline
\end{tabular}

To sum up, support was gained for the four hypotheses of the study. The experimental group out-performed the control group on the post-test in overall reading comprehension performance as well as in each reading comprehension skill. Furthermore, the experimental group students achieved tangible progress in their reading comprehension after receiving instruction through schema-based techniques. Hence, these positive findings of the study proved the effectiveness of schema-based techniques in developing first-year secondary school students' overall reading comprehension and each reading comprehension skill as well.

\section{Conclusion}

It can be concluded that schema theory suggests that reading comprehension is an interactive relationship or process involving the reader's background knowledge and the text; it involves actively constructing meaning among the parts of the text and personal experience. These results receive support from previous research (e. g., Landry, 2002; Scarcella and Oxford, 1992; Zhao and Zhu, 2012;) that stresses the value of schema-based techniques in providing students with ways to activate their prior knowledge base. Studies looked at three possibilities: (1) building readers' background knowledge; (2) activating readers' existing background knowledge and attention focusing before reading; and (3) guiding readers during reading and providing review after reading (Oller, 1995; Liand Zang,
2016). It appears that when readers lack the prior knowledge necessary to read, three major instructional interventions need to be considered: (1) teach vocabulary as a pre-reading step; (2) provide experiences; and (3) introduce a conceptual framework that will enable students to build appropriate background for themselves.

Results of the current study go in line with previous research that confirms the fact that insufficient or inaccurate background knowledge may cause readers to make inferences or interpretations that are inconsistent with information in the text. And the more information (schemata) subjects have about a topic, the more they evaluate what they are reading, draw inferences, and make direct connections between available information and unfamiliar information to reveal meaning (D' Andrade, 1995; Bryan, 1998; Maria, 1990Schmidt, 1999).

\section{References}

[1] Armbruster, B (1986). Schema Theory and the Design of Content- Area Textbooks. Educational Psychologist, 21 (4), 253-267.

[2] Bartlett, F (1932). Remembering. Cambridge: Cambridge University Press.

[3] Bottomley, D \& Osborn, J. (1993). Implementing Reciprocal Teaching with Fourth- and Fifth-Grade Students in Content Area Reading. Center for the Study of Reading, Urbana, Illinois, U. S. A. ERIC Research Report (ED361668). 
[4] Bryan, J. (1998). KWWL: Questioning the Known. The Reading Teacher, 51 (7), 618-620.

[5] Ciardiello, A. V. (1998). Did you Ask a Good Question Today? Alternative Cognitive and Metacognitive Strategies. Journal of Adolescent and Adult Literacy, 42 (3), 210-219.

[6] Clark, H. T \& Reese, C. M. (1990). The Relationship of Text Schemata to Comprehension Monitoring among 3rd, 4th, and 6 th Grade Students. Paper presented at the Annual Meeting of the Eastern Educational Research Association, Arizona (U. S. A.). ERIC Research Report (EN- ED319002).

[7] D' Andrade, A. (1995). Schema Theory. Retrieved on November $6^{\text {th }}, 2016$ from http://www.analytictech.com/mb870/schema.htm.

[8] Harris, T \& Hodges, R. (1995). The Literacy Dictionary. Newark, Delaware: International Reading Association.

[9] Johnstone, J. R. (1989). A Comparison of Supervising Teachers, Reading Specialists, and Pre-service Teachers' Ratings of Student Performance Using the Directed Reading Thinking Activity. Paper presented at the Annual Meeting of the College Reading Association. ERIC Research Report (ED320120).

[10] Kitao, S. K. (1989). Reading, Schema Theory and Second Language Learners. ERIC Research Report (ED314937).

[11] Landry, K (2002). Schemata in Second Language Reading. The Reading Matrix, 2 (3), 1-14.

[12] Li, J \& Zang, L. (2016) The Application of Schema Theory to English Reading Teaching in Junior High School. Sino-US English Teaching, 13 (1), 14-21.

[13] Lysynchuk, L. (1989). Reciprocal Instruction Improves Standardized Reading Comprehension Performance in Poor Grade-School Comprehenders. Paper presented at the Annual Meeting of the American Educational Research Association. ERIC Research Report (ED305597).

[14] Maria, K. (1990). Reading Comprehension Instruction: Issues and Strategies. York Press, Parkton, Maryland.

[15] McCarthy, M. (1991). Discourse Analysis for Language Teachers. Cambridge: Cambridge University Press.

[16] McNeil, J. D. (1987), Reading Comprehension: New Directions for Classroom Practice, (2nd ed.), University of California, Scott, Foresman and Company, London.

[17] Moffitt, K. (1989). An Empirical Test of Expert System Explanation Facility Effects on Incidental Learning and Decision Making. Unpublished PhD. Dissertation, Arizona State University.
[18] Nunan, D. (1999). Second Language Teaching \& Learning. Boston: Heinle \& Heinle Publishers.

[19] Odafe, V. U. (1998). Student generating test items: A teaching and assessment strategy. Mathematics Teacher, 91 (4), 198-203.

[20] Ogle, D. (1986). K-W-L: A teaching Model that develops Active Reading of Expository Text. The Reading Teacher, 39 (1), 564-570.

[21] Oller, J. (1995). Adding Abstract to Formal and Content Schemata: Results of Recent Work in Peircean Semiotics. Applied Linguistics, 16 (3), 273-306.

[22] Palincsar, A. S. (1987). Collaborating for Collaborative Learning of Text Comprehension. Paper presented at the Annual Meeting of the American Educational Research Association. Washington, U. S. A. ERIC Research Report (ED285123).

[23] Rumelhart, D. (1980). Schemata: the Building Blocks of Cognition. In: R. Spiro et al. (Eds.), Theoretical Issues in Reading Comprehension. Perspectives from Cognitive Psychology, Linguistics, Artificial Intelligence and Education. (Pp. 33-57), New Jersey: Lawrence Erlbaum Associates.

[24] Scarcella, R. C. \& Oxford, R. L. (1992), The Tapestry of Language Learning. Heilnle \& Heilnle Publishers, Boston, Massachusetts, U.S.A.

[25] Schmidt, P. R. (1999). KWLQ: Inquiry and Literacy Learning in Science. The Reading Teacher, 52 (7), 789-792.

[26] Spires, H. A. (1990). Prior Knowledge Activation: Inducing Text Engagement in Reading to Learn. Paper presented at the Annual Meeting of the American Educational Research Association. ERIC Research Report (ED328880).

[27] Stauffer, R. G. (1969). Directing Reading Maturity as a Cognitive Process. New York, NY: Harper and Row.

[28] Stauffer, R. G. (1975). Directing the Reading-Thinking Process. New York, NY: Harper and Row.

[29] Wallace, C. 1992). Reading. Oxford: Oxford University Press.

[30] Wilson, P. \& Anderson, R. (1986). What They Don't Know Will Hurt Them: The Role of Prior Knowledge in Comprehension. In J. Orasanu (Ed.), Reading Comprehension: From Research to Practice. (Pp: 31-48), New Jersey: Lawrence Erlbaum Associates.

[31] Zhao, X, \& Zhu, L. (2012). Schema Theory and College English Reading Teaching. English Language Teaching, 5 (1), 111-117. 